\title{
Contextualizing Media Choice Using Genre Analysis
}

While media use becomes increasingly important in virtualized work contexts, traditional media choice theories exhibit a range of shortcomings with regard to practical application. The paper presents an approach for contextualizing media choice using genre analysis. In doing so, the communication of a team can be captured as a repertoire of genres and as such be made accessible for subsequent analysis.

An improved media selection results from a comparison of genre requirements with the characteristics of available communication media (in terms of a genre-media-fit). The identified genres allow illustrating the intended benefits of the proposed media as well as possible ways of application in rich and vivid ways.

The presented approach represents an important step in the development of a method for team communication analysis to be used in a consultancy context.

DOI 10.1007/s12599-008-0015-2

\section{The Authors}

Dr. Kai Riemer
Dipl.-Wirt.-Inform. Stefanie Filius
European Research Center for
Information Systems (ERCIS)
Universität Münster
Leonardo-Campus 3
48149 Münster
Germany
wikari@wi.uni-muenster.de
http://www.wi.uni-muenster.de/wi/
orga/wikari.cfm

Received: 2008-05-01

Accepted: 2008-09-02

Accepted after three revisions by Prof. Dr. Buhl.

This article is also available in German in print and via http://www.wirtschafts informatik.de: Riemer K, Filius S (2008) Kontextualisierung der Medienwahl mit Hilfe von Kommunikationsgenres. WIRTSCHAFTSINFORMATIK. doi: 10.1007/11576-008-0120-3.

\section{Introduction}

Work in contemporary organizations is increasingly affected by virtualization in terms of collaborations across organizational, temporal and spatial boundaries (Riemer and Klein 2008, p. 147). Moreover, a significant part of organizational activities is made up of creative and knowledge-intensive tasks that cannot be pre-structured and automated using information and communication technologies (ICTs). Rather, in this context ICTs typically serve as enablers for supporting communication and distributed collaboration between people. At the same time, questions of how to best support media selection in specific work contexts remain still largely unanswered from an Information Systems perspective. While media choice has been singled out as a core theme in Information Systems research for a long time, the resulting media choice theories exhibit several shortcomings with regard to application in practice: First, they aim at generalizing across contexts rather than analyzing a single case, which can lead to trivial recommendations at times. Second, they view communication situations as being analytically dissectible. Third, they tend to abstract from a range of important context factors and the fact that communication is socially embedded. And finally, they are largely underspeci- fied with regard to operationalization, so that an application in practice seems hardly possible.

Against this backdrop, our paper is concerned with communication analysis in distributed teams, and more specifically with the contextualization of media choice by applying genre analysis. We will present an approach for describing, in a structured manner, the communication practices of a team using genres, as well as for analyzing current media use in order to derive propositions for improved media selection and corresponding usage scenarios. The application of our approach will be demonstrated with a case example.

Our paper stands in the tradition of design-oriented research and aims to make a contribution in a field that presents itself under-investigated from an Information Systems research standpoint, but shows increasing significance for organizations in practice. Our paper makes a theoretical contribution to media choice research as well as an important step towards developing a comprehensive communication analysis method for use in practice. The purpose of such a method is to enhance communication and collaboration effectiveness in virtual teams by improving media choice and thus to ultimately contribute to the success of organizational virtualization. 


\section{Overview of the research project}

Communication analysis is not a new topic in the Information Systems domain. As early as 1990, Frank and Kronen point out that typical studies that aim at explaining ICT phenomena are often unable to provide answers to the questions of designing ICT systems in specific organizational settings (Frank and Kronen 1991, p. V.). The authors carried out an empirical investigation of communication analysis approaches that were used by practitioners (e. g. IT consultants) for gathering information to support the design of contextspecific information systems.

\subsection{Background and methodological approach}

Our work stands in the tradition of such approaches, but with a focus on the media choice decision instead of systems design. It is part of a larger project that aims to develop a method for communication analysis at the team level. This method is directed at internal or external consultants who want to improve media use in distributed teams. In the following we will concentrate on the key activity of this method, i. e. the operationalization of the media choice decision.

We will motivate our design-oriented approach by critiquing existing media choice research (section 3 ). After that, we will present an operationalization and contextualization of media choice based on genre analysis (section 4). The purpose of a genre analysis is to identify communication patterns in a social community (e. g. a team). The resulting genre repertoire describes the existing team communication and can be the basis for analyzing and improving current media use (section 5).

Method development in Information Systems is typically applied research. Apart from literature analyses it draws on action research, interviews, field research and case studies (Braun et al. 2005, p. 1298). Accordingly, in this paper we present a mainly literature-based approach that is exemplarily applied in a case example. The case study part serves to demonstrate its applicability as well as it is an immediate step in the advancement of the approach. At the end of the paper, we will discuss findings derived from the application in light of the ongoing process of method development (section 6).

\subsection{Overview of the case example}

Carpus+Partner AG is a medium-sized company ( $€ 9$ Mio. turnover in 2006, 120 employees at two sites in Aachen and Ulm), which concentrates on the planning and carrying out of international construction projects in the roles of consultant and primary contractor. For doing so, the company employs architects, engineers, business staff, technicians, and designers. The business is organized in customer projects that are made up of 4 to 15 people from the different professional backgrounds; about 60 projects are carried out each year. There are no fixed team constellations; rather in each case teams are newly established from scratch according to project requirements. Teamwork happens mostly distributed, since employees from both Aachen and Ulm are typically involved in a project, while selected people also work permanently on the building site; on top of this come freelancers and customer employees.

Large parts of the project work are concerned with planning, i. e. the production of a plan that lays out all aspects of the building to be constructed. This plan is compiled step by step through the consolidation of detailed component drawings (sub plans). It is thus a visual representation containing the locations of entities such as circuits, walls, cables, ceilings etc. All drawings are either crafted using CAD software or as paper and pencil sketches. In doing so, the planning and design work is highly interdependent, i. e. the activities are tightly coupled which requires constant communication (Olson and Olson 2000, p. 163). Consequently, effective media use is of utmost importance for co-located, but more importantly for virtual teamwork across different team locations.

\section{Scrutinizing traditional media choice approaches}

We begin by providing an overview of the evolution of media choice research. By critiquing typical media choice theories we will then derive requirements for a designoriented approach to media choice.

\subsection{Evolution of media choice research}

Research into media choice phenomena has a long tradition in the Information Systems field, with some early approaches having gained widespread attention, in particular the media richness theory. Although some of their key propositions have since been challenged or could not be confirmed in numerous empirical studies (e. g. Chidambaram et al. 1998b; Kinney and Watson 1992; Lee 1994), they are still widely used today (e. g. Otondo et al. 2008). From the criticism of these early theories many other approaches have originated, all of which argue in basically the same way. Their main aim is to generalize, i. e. to be able to explain and predict media choice across various social contexts and thus also support media choice in concrete cases.

\subsubsection{Rational choice models}

Early media choice theories are based on the principle of rational choice behavior. They assume that users base their media selection on cognitive evaluations of the media and their appropriateness to the task at hand. Hence, the resulting choice is regarded rational and efficiency-motivated (Arnott and Tan 2001). For example, social presence theory (Short et al. 1976) is based on the idea that a medium is selected such that its social presence fits what is required in a given communication situation. Media richness theory (MRT) (Daft et al. 1987) follows the assumption that media choice depends on the complexity of a communication task. Generally, a medium will be selected whose richness matches best the complexity of the task, i. e. the more ambiguous a task is, the richer the medium should be. Richness refers to media aspects such as the type of signals being transferred, like tone, body language, text etc. (Trevino et al. 1990, p. 75).

Media synchronicity theory (MST) (Dennis et al. 2008; Dennis and Valacich 1999) was coined based on a critique of the simplicity with which tasks are conceptualized within MRT; hence, while the theory still conceptualizes media in a similar way, in the logic of MST media capabilities should match the needs of more fundamental communication processes (Dennis and Valacich 1999, p. 6). Moreover, there are other approaches that follow a similar logic, such as the task-ori- 
ented media choice model (Reichwald et al. 1998, p. 59). The above approaches all have in common that media choice is based on the matching of media properties with requirements of the communication situation (e. g. the task). Hence, they follow a fit rationale, most often in terms of a taskmedia-fit.

\subsubsection{Collective choice models}

The rational choice principle of the above described approaches has been opposed by many authors (Schwabe 2004, p. 262). Therefore, another group of theories acknowledges that media choice is generally influenced by a range of social factors and that media characteristics can be viewed rather differently across social contexts. For example, the channel expansion theory argues that media richness is perceived differently depending on one's experience with the medium and also the history of interactions between the communication partners (Carlson and Zmud 1999). For example, a range of studies has portrayed e-mail as a medium that, under certain circumstances, can exhibit a degree of richness that runs counter to the common believes held by MRT (Huang et al. 1998; Lee 1994; Markus 1994). Moreover, social influence theory stresses the influence of the social environment on media choice (Fulk et al. 1990); for example, users are influenced in their media selection by reflecting on the media use of others within their environment. A more complex relationship between media choice and social context factors has been suggested by adaptive structuration theory (DeSanctis and Poole 1994). Its key proposition is that the success of media use is dependent on a set of complex and recursive factor relationships in the social context; it also stresses that communication media are appropriated by their users, i. e. that they are often used in unexpected and very different ways (Schwabe 2001, p. 61). The main contribution of this set of theories is their emphasis on how social factors impact on media choice in addition to the aforementioned task-media-fit.

\subsubsection{Further research on media choice in organizations}

In subsequent years numerous studies have identified even more variables that potentially influence media choice in organizations. Among them are team structures
(Watson-Manheim and Bélanger 2002), a shared team history (Alge et al. 2003), the relationships between the team members (Pauleen and Yoong 2001), organizational roles (Carlson and Davis 1998), users' media usage experience (King and Xia 1997) as well as culture as an additional context factor (Lee and Lee 2003). A good overview is provided by Carlson and Davis (1998, p. 342).

\subsection{A critique of the principles of abstraction and generalization}

We argue that one fundamental problem of the above discussed theories and approaches stems from the underlying research paradigm in that they strive to explain media choice in a generalized way and across social contexts. Consequently, most of the findings of these studies are not very useful when it comes to the single case, because they provide general statements that, more often than not, bear little relevance for application in practice.

Moreover, the above discussed theories and approaches all emphasize several, often isolated and very different variables for explaining media choice. Consequently, some authors deplore the multitude of factors identified in the different approaches as little helpful in improving the ability to predict media choice behavior (Carlson and Davis 1998, p. 341). And the more complex the factor combinations become, the less likely such studies are to provide concrete help for supporting the selection problem in practice because only very few clear recommendations can be drawn from the studies. These recommendations often resemble simple clichés or remain very abstract and vague; for example: "For managers, this study illuminates the need to consider group cohesion when various technologies are deployed to support groups." (Yoo and Alavi 2001, p. 385). Moreover, many studies that aim to explain media choice do not even claim to support the practical problems of media selection (e. g. see Dennis et al. 1998, p. 9).

Generalization of media choice across contexts is also questionable for another reason: deterministic and consistent media selection behavior cannot be observed in practice; in different organizations people exhibit very different media choice and usage behavior, even in remarkably similar communication situations (WatsonManheim and Bélanger 2007, p. 276; Yoo and Alavi 2001, p. 374). In addition, some authors argue that the conceptualizations of both tasks and media are generally too abstract in most theories (Otondo et al. 2008, p. 28).

Consequently, in order to support media selection in practice, we advocate a designoriented approach that caters for the specific requirements of communication in a concrete social context and that comes with an operationalization that allows for evaluating communication and media use in situ, i. e. in the single case.

\subsection{Parameters for a design-oriented approach}

First of all, we have to acknowledge that the basic notion of task-media-fit (as proposed by MRT) is intuitively appealing and regarded as conventional wisdom by many in the field (Chidambaram et al. 1998a, p. 2). However, while group tasks certainly exert a certain influence on media choice, our discussion of the various studies has made it clear that the relationships in practice are much more complex and less clear-cut (Chidambaram et al. 1998a, p. 1). Moreover, there is little doubt that media choice and usage are socially embedded (Watson-Manheim and Bélanger 2007, p. 269) and that it is important to get to know the specific social context in order to understand media choice behavior (e. g. see Markus 1994; Rice and Aydin 1991; Zack and McKenny 1995). Newer studies view media selection and media use as highly routinized and as part of social practices that emerged over time (WatsonManheim and Bélanger 2007, p. 269) as a result of learning and habituation (King and Xia 1997, p. 877). In this context, it is also important to know that media properties are interpreted differently by established groups as opposed to newly formed groups (Yoo and Alavi 2001). However, most media choice approaches seem to be based on the assumption of a green field approach in which no history or social structure exists. Also, in practice people use media not in isolation but in combination (Chidambaram et al. 1998a); in their daily work they are used to drawing on media repertoires (WatsonManheim and Bélanger 2007). Moreover, processes of technological convergence have resulted in a situation where single media cannot be treated separately anymore because modern artifacts often resemble integrated systems that come 
with whole bundles of communication features (Riemer et al. 2005).

\subsection{Contextualization of media choice using genres}

Starting from the observations above, we present an approach for supporting media selection in practice that differs from traditional media choice approaches in its underlying conception of communication, organization, and technology while retaining the basic media-fit logic.

Traditional media choice theories are based on the assumption that group communication can be analytically decomposed into a set of pre-assigned dimensions in order to be assessed subsequently. Our approach however is based on a practice theoretical understanding (cf. Giddens 1984; Orlikowski 2000; Orlikowski 2002) that views communication (and media use) as socially embedded and as an integral part of shared learned practices of a specific group, which cannot be isolated, decontextualized and analyzed in an abstract manner. With regard to taskmedia-fit this means that in practice tasks cannot be singled out from their context as distinct and separable entities; in the same way communication in a social context can never be reduced to one singular purpose such as the fulfillment of a given work task.

Henceforth, we will introduce communication genres as a different object of reference for evaluating media-fit, since the concept is true to a routine or practicebased understanding of communication and because it captures the notion of practices of communicative action, which sees communication and work task execution as inseparable parts of the same practice. At the same time we work toward a methodological operationalization that enables us to gather rich qualitative data in context as the basis for the identification of communication genres and the subsequent analysis of media use. For doing so, we need to change our level of analysis: instead of a generalization across contexts we need to focus on the single case. Communication and media use have to be viewed as part of a concrete social context and be analyzed based on rich data of a particular group (Lee 1994, p. 148). Hence, while traditional media choice theories advocate a top-down approach by drawing concrete recommendations from general theoretical statements, the idea behind

Media choice theories

Genre-based approach

\begin{tabular}{|c|c|c|}
\hline Generalization & Change the level of analysıs & Focus on single case \\
\hline $\begin{array}{l}\text { Communication can be } \\
\text { decomposed into pre- } \\
\text { assigned dimensions }\end{array}$ & Adopt a practice-theoretical view & $\begin{array}{l}\text { Communication is socially } \\
\text { embedded (practices of } \\
\text { communicative action) }\end{array}$ \\
\hline $\begin{array}{l}\text { Principle of abstraction; } \\
\text { main statements are generic } \\
\text { and independent of context }\end{array}$ & Contextualize the analysis & $\begin{array}{c}\text { Analysis of communication } \\
\text { and media use in a concrete } \\
\text { social context }\end{array}$ \\
\hline $\begin{array}{l}\text { Task-media-fit or fit with } \\
\text { fundamental, generalized } \\
\text { communication processes }\end{array}$ & Change the object of reference & $\begin{array}{l}\text { Genre-media-fit, genres } \\
\text { capture routinized } \\
\text { communication (practices) }\end{array}$ \\
\hline $\begin{array}{l}\text { Often no intent to support } \\
\text { media choice decision; } \\
\text { application not supported }\end{array}$ & Operationalization & $\begin{array}{l}\text { Genre analysis as main } \\
\text { instrument for facilitating } \\
\text { communication analysis }\end{array}$ \\
\hline $\begin{array}{l}\text { Singular, isolated view of } \\
\text { communication media }\end{array}$ & More complex view of technology & $\begin{array}{l}\text { Combination and bundles of } \\
\text { media; technologies-in-use }\end{array}$ \\
\hline Top-down approach & Change direction of reasoning & Bottom-up approach \\
\hline
\end{tabular}

Fig. 1 Juxtaposition of the genre-based approach and traditional media choice theories

our genre-based approach is to identify, in a bottom-upway, the actual communication structures in a concrete group for which we can then derive media choice recommendations.

Last but not least our approach acknowledges a more complex view of technology as comprising bundles and combinations of media. At the same time, we also follow a practice-based notion of technology, which sees technologies as embedded in social practices [i. e. as technologies-in-use (Orlikowski 2000; Riemer et al. 2007a)]. Hence, particular technologies (e. g. media properties) also need to be understood in the context of these practices. Fig. 1 visualizes our genre-based approach by juxtaposing its main features and the characteristics of typical media choice theories. In the following sections we will show how the media choice decision process can be contextualized by applying genre analysis.

\section{Identification of communication genres}

In this section we will clarify our methodological approach for identifying communication genres in a team context. For doing so, we will first of all introduce and define genres and the genre analysis concept before we will describe in more detail the qualitative research methods that are used for data gathering and analysis in the process of genre identification. We will also illustrate genre identification in our case example.

\subsection{Definition of concepts}

\subsubsection{Communication genres}

The term genre is French and means type or category, while genre analysis originally refers to the act of categorizing artistic, musical, or literary compositions. In general linguistic use the term genre refers to categories of popular media such as books and movies. Bakhtin (1986) was the first to apply the concept to the analysis of communication. He defines genres as "relatively stable types of... [oral and written] utterances" (Bakhtin 1986, p60). Yates and Orlikowski (1992) brought genres to the Information Systems domain; they see genres as "socially recognized types of communicative actions that are habitually enacted by organizational members over time to realize particular social purposes in recurrent situations" (Yates et al. 1999, p. 84).

Communication genres describe recurring communication patterns within a discourse community (e. g. employees of a company), which develop over time as a response to recurring communication situations (Berkenkotter and Huckin 1995, p. 4; Bitzer 1968, p. 13).

Genres are socially embedded, i. e. they are valid and meaningful only in the context of the particular community (Swales 


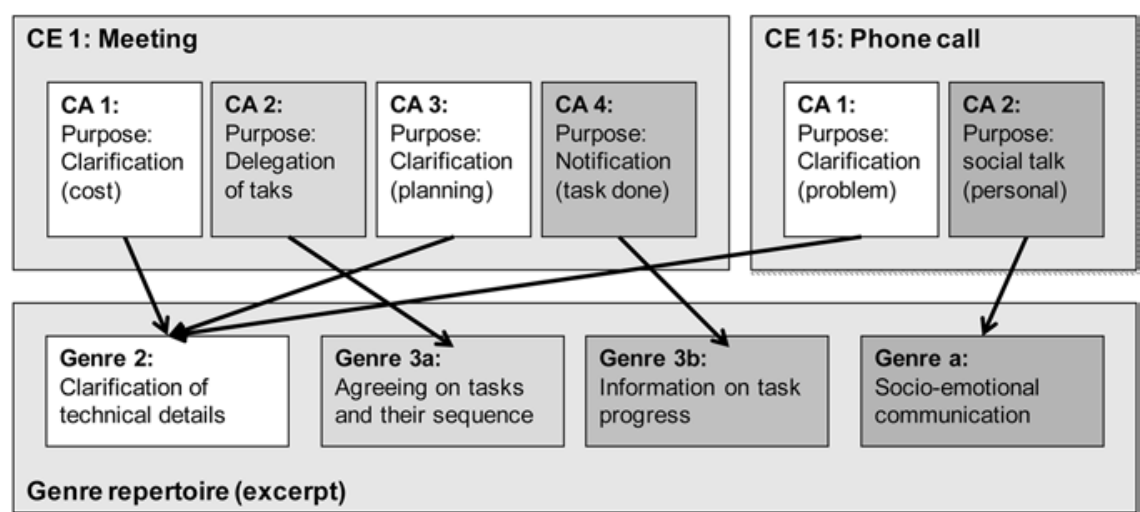

Fig. 2 Relationship between main genre analysis constructs

1990, p. 24 ff). They reflect existing communication practices (Yates et al. 1999, p. 84) and capture the ways in which people communicate (Berkenkotter and Huckin 1995, p. 7). Otherwise similar communities can build out very different communication genres, which is why communication analysis has to be carried out in a particular context.

Genres are part of social practices; they shape social activity by providing socially agreed templates that people use (subconsciously) in their communication (Kwasnik and Crowston 2005). As such genres are not the result of single communicative acts, but the result of routinization and habituation (Yates and Orlikowski 1992, p. 299). Following Giddens' structuration theory (Giddens 1984) genres are used by actors to structure their communicative actions, while at the same time they are socially reproduced, solidified and thus further established within the community. Hence, genres are at the same time medium for and result of communication (Yates and Orlikowski 1992, p. 302).

\subsubsection{Genre analysis}

Genres can serve as an analytical tool for understanding the communication practices of a social group because "in identifying and labeling genres we try to capture the gestalt of the various components of the communicative act." (Kwasnik and Crowston 2005, p. 80) Genre analysis is based on the observation that a limited set of genres (a genre repertoire) can fully describe the day-to-day communication of a social group (Orlikowski and Yates 1994, p. 547). Genres themselves cannot be observed in practice; rather genres are the result of an interpretation and classification of observable communication acts. Communication acts on the other hand can be seen as particular instances of these genres. As such, genres serve as emergent classes of communicative acts (Swales 1990, p. $45 \mathrm{ff}$ ).

In order to identify (a set of) genres, we need to specify how a genre can be recognized. Generally, genres can be described using content, form and purpose (Kwasnik and Crowston 2005, p. 76). While every communication is characterized by a specific intention or purpose (Herrmann 1991, p. 64), purpose is recognized by the social community and does not vary between communication acts; it is in fact the reason why a genre emerged in the first place (Yoshioka et al. 2001, p. 436). Form refers to observable features such as the medium, the degree of formality and the choice of vocabulary (Yoshioka et al. 2001, p. 436). While both purpose and form can constitute genres, its content usually varies between communication acts (Yates and Orlikowski 1994, p. 544). And since our approach intends to draw conclusions with regard to media choice (i. e. it captures variation in the form dimension), we follow Swales (1990) who recommends identifying genres by purpose: what "turns a collection of communicative events into a genre is some shared set of communicative purpose" (Swales 1990, p. 46). We conclude that a genre analysis results in a context-specific overview of the communication of a social group, structured by purpose.

\subsection{Method for identifying genres}

In order to identify a team's communication genres, we need to gather and analyze comprehensive data on its day-to-day communication. For doing so, qualitative research methods seem most appropriate.
In order to demonstrate applicability and adequacy of our genre-based approach in this study, we opted for an application of these methods that adheres to rigorous research standards. Obviously, both data collection and analysis would have to follow more pragmatic principles when being applied in a management-consulting context, i. e. as part of the larger method under construction. However, in the following we will describe data collection procedures and their application from a research perspective. Based on this foundation we will then be able to develop more pragmatic instruments in the future.

\subsubsection{Recording of communication acts (data collection)}

The aim of this (first) data collection phase is to gain a comprehensive and realistic picture of the existing team communication. Data collection is carried out as a field study by applying methods such as observations and interviews. A similar qualitative research design (cf. Bryman and Bell 2003, p. 279 ff) for investigating communication practices has been used before (Lee 1994; Riemer et al. 2008; Watson-Manheim and Bélanger 2002). The advantage of combining observations with interviews is that one arrives at a more holistic picture of the existing communication (Rosenstiel 2003, p. 70). On the one hand, observations facilitate the investigation of communication from the outside. By doing so, it is possible to record and account for habitual communication, which team members otherwise would not be able to specify in an interview since they are not consciously aware of it (Bortz and Döring 2006, p. 238, Bungard et al. 1996, p. $80 \mathrm{ff}$ ). On the other hand, only through interviews can one gain an inside perspective and understand the intentions and motives of the communicating people.

All communication needs to be observed and recorded in situ, i. e. in the team members' work contexts. In doing so, the main entities to be distinguishably observed are the communication episodes $(C E)$. A CE can be a face-to-face conversation or a phone call. Since the purpose (or topic) can change during an episode, ultimately the smallest entity is the communication act (CA). As such, a CA might be interpreted as a potential instance of a genre. A change in communication purpose always denotes the end of a $\mathrm{CA}$, while 
an episode always comprises one or more CAs (see Fig. 2).

Following the recommendations by Bungard et al. (1996, p. 99), data documentation in this phase is relatively unstructured: content, purpose, form and any specialties of the observed CEs are written down in a journal. Throughout the observation the idea is to record as many CEs as possible in different contexts and media. Typically, we record meetings, discussions and any other conversations by team members in their work environment, in addition to the analysis of e-mails sent to each other. When possible, observations should always be complemented by short interviews that are carried out immediately after recording a $\mathrm{CE}$, i. e. in order to elicit intentions and motives.

\subsubsection{Identification of genres (data analysis)}

The idea of applying genre analysis is to capture the observed variety in team communication in one structured model (the genre repertoire), in order to make it accessible for the subsequent analysis. The notes, which have been taken throughout observations and interviews, serve as the basis for genre identification. This material, which can be quite substantial, needs to be processed using qualitative data analysis methods (see Miles and Huberman 1994): The data need to be cleaned up and condensed before they are coded and finally structured (e. g. by tabling the resulting categories). This data analysis resembles a grounded theory approach as advocated by Strauss (1998), i. e. an exploratory approach for eliciting theoretical constructs and relationships from rich empirical data.

More specifically, genres are identified by coding and grouping the observed CAs according to their purpose for the team (Askehave and Swales 2001, p. 205, Swales 1990, p. 58). In doing so, it is important to find the right level of granularity and to make sure that one arrives at a meaningful set of genres. Throughout the analysis "many genre candidates may appear, and scrutinizing which are true genres is a permanent overhead" (Antunes et al. 2006 , p. 3). At this point, we need to stress the fact that not every CA has to be interpreted as an instance of a genre because genres only capture routinized team communication, but not any infrequent special cases.
In order to make sure that we identify suitable genres, all genre candidates are discussed with the team members. Here, another advantage of genre analysis comes to the fore: genres are recognizable and immediately understandable by members of the discourse community (Swales 1990 , p. 58). In our application in the case example team members were immediately able to relate to our genre propositions and were able to quickly agree on those genres that best characterize the routine team communication.

In addition, we need to point out that the separation of data collection and analysis, as described here, is only for illustration purposes. In line with the cyclical research process of qualitative research (Flick 1998, p. 45), there are typically quick alternations of observing, interviewing, reflecting on, cleaning up and analyzing data throughout the whole field study, before a final analysis concludes the field work.

\subsubsection{Capturing the communication context}

As with every qualitative research, in order to truly understand the object under study (e. g. team communication), we need to gain a good picture of its context (Bungard et al. 1996, p. 71). Therefore, we need to gather data on aspects such as company structures, culture, the type of team virtualization and also available communication media. For doing so, we suggest carrying out semi-structured interviews with team members and other company representatives, such as managers and members of the IT division. Following a true case study approach, further data sources such as company web sites, reports or meeting protocols can complement the picture (Yin 2003, p. $85 \mathrm{ff}$ ). Ideally, all data are then condensed into a short case description that can be scrutinized by company members in order to arrive at a solid basis for the further study.

\subsection{Data collection in the case example}

We began our study ${ }^{1}$ at Carpus+Partner by carrying out short interviews with a member of the executive board, his assistant and managers of three teams that where candidates for inclusion in our study; we also interviewed some of the team members. In addition, we analyzed

\footnotetext{
All data was collected by the second author.
}

company brochures and old meeting protocols. This pre-phase served two purposes: first, we wanted to identify a team that was representative for the rest of the company. Second, we gathered the above mentioned context data.

In order to understand communication at Carpus+Partner it is important to know that collaboration is based on agreements between the team members; e. g. when being asked to carry out or participate in a task, team members are free to opt out in case the particular job cannot get done within the timeframe. Consequently, teams do not exhibit hierarchical structures, but are characterized by an agreement culture that is very communication intensive.

Specifically, we studied a project team whose role was to plan a new laboratory building for a biotechnology company. The team consisted of eight internal and four external employees distributed across five locations. Data collection was carried out at the Aachen site, where eight of the twelve team members worked. Communication with the remote team members was recorded whenever they interacted with team members in Aachen. We paid attention to observing communication in various forms and changing contexts in order to arrive at a comprehensive picture. Data collection took three full days (9 hours each), in which four long meetings and a range of other conversations and phone calls were observed; we also analyzed all e-mails sent by the team members. Whenever we needed background information to understand what we observed, we immediately asked short questions. This resulted in almost 40 pages of handwritten notes as the basis for genre identification.

\subsection{Genre repertoire in the case example}

In the subsequent data analysis we identified five communication genres, two of which were sub-divided into sub genres. This genre repertoire provides a rich overview of the existing communication practices in the team.

\subsubsection{Genre 1: Discursive plan development}

This genre captures all communicative action concerned with the joint development of a plan; its purpose hence is to jointly arrive at the best possible version of the final plan. The plan is created by 


\begin{tabular}{|c|c|c|c|c|c|c|}
\hline $\begin{array}{l}\text { Medium } \\
\text { Characteristics }\end{array}$ & $\begin{array}{l}\text { Meeting, } \\
\text { face-to-face }\end{array}$ & $\begin{array}{l}\text { Video } \\
\text { conference }\end{array}$ & Telephone & $\begin{array}{l}\text { Instant } \\
\text { message }\end{array}$ & E-mail & $\begin{array}{l}\text { File } \\
\text { sharing }\end{array}$ \\
\hline $\begin{array}{l}\text { Supports } \\
\text { personal } \\
\text { atmosphere }(1,2)\end{array}$ & yes & yes & medium & little & little & no \\
\hline $\begin{array}{l}\text { Quick } \\
\text { feedback/reply } \\
\text { possible }(2,3)\end{array}$ & $\begin{array}{l}\text { yes } \\
\text { (synch.) }\end{array}$ & $\begin{array}{l}\text { yes } \\
\text { (synch.) }\end{array}$ & $\begin{array}{l}\text { yes } \\
\text { (synch.) }\end{array}$ & $\begin{array}{l}\text { medium } \\
\text { (near synch.) }\end{array}$ & $\begin{array}{l}\text { no } \\
\text { (asynch.) }\end{array}$ & $\begin{array}{l}\text { no } \\
\text { (asynch.) }\end{array}$ \\
\hline Rehearsability (3) & no & no & no & yes & yes & yes \\
\hline $\begin{array}{l}\text { Reprocessability } \\
\text { (3) }\end{array}$ & no & no & no & yes & yes & yes \\
\hline Parallelism (3) & low & very low & very low & high & high & very high \\
\hline \multicolumn{7}{|c|}{ Symbol variety $(2,3,4)$} \\
\hline $\begin{array}{l}\text { Facial } \\
\text { expressions, } \\
\text { gestures }\end{array}$ & yes & yes & no & no & no & no \\
\hline Tone & yes & yes & yes & no & no & no \\
\hline Visuals & yes & possibly & no & possibly & yes & no \\
\hline $\begin{array}{l}\text { Automatic docu- } \\
\text { mentation (3) }\end{array}$ & no & sometimes & sometimes & yes & yes & no \\
\hline $\begin{array}{l}\text { Accessibility, } \\
\text { effort for commu- } \\
\text { nication }(4,5,6)\end{array}$ & $\begin{array}{l}\text { maybe high } \\
\text { (Travel) }\end{array}$ & $\begin{array}{l}\text { high } \\
\text { - medium }\end{array}$ & low & low & $\begin{array}{l}\text { medium } \\
\text { - low }\end{array}$ & medium \\
\hline
\end{tabular}

(1) Social Presence Theory (Short et al. 1976) $\quad$ (2) Media Richness Theory (Daft and Lengel 1984;

Daft et al. 1987) (3) Media Synchronicity Theory (Dennis and Valacich 1999)

$\begin{array}{lll}\text { (4) Model of task-oriented media choice (Reichwald et al. 1998) } & \text { (5) Messaging Threshold }\end{array}$

Approach (Reid et al. 1996) $\quad$ (6) Media Accessibility Theory (Carlson and Davis 1998)

merging a number of detailed component drawings. Due to the interdependencies between the detailed drawings, team members need to constantly communicate and discuss in order to solve the inevitable conflicts between their sub tasks. Hence, the plan is developed in a discourse process. Consequently, the genre captures all CAs that are concerned with the discussion of component drawings and versions of the plan. These can be discussions on existing drawings or the joint creation of new versions of the plan. Throughout the process many of the discussed versions are modified or discarded. This genre is the most complex one and its CAs account for most of the team communication time.

\subsubsection{Genre 2: Clarification of technical details}

Since the knowledge needed to develop the plan is distributed among people and across geographical sites, a lot of communication is concerned with the clarification of technical details. In doing so, many important detail questions concerning the plan are being discussed. In contrast to the above genre this happens in short bilateral CAs; the questions being asked can mostly

\subsubsection{Genre 4: Coordination of communication}

Communication also needs coordination; this results mainly from a lack of awareness of other team members' work contexts and availability in virtualized collaborations (Riemer et al. 2007b; Scupelli et al. 2005, p. 1773). The purpose in this genre is to clarify when and through which medium a particular person is available for communication. We also divided this genre into sub genres. The first sub genre (4a), aims at "making an appointment" between two or more team members with regard to place, time, medium, and topic. The second one (genre $4 \mathrm{~b}$ ) is called "clarifying availability for communication" and captures communication acts concerned with the availability of team members for communication: Either someone signals their own availability (e. g. by updating a so-called "away-list"); or others answer questions on someone's availability.

\subsubsection{Genre 5: Socio-emotional communication}

Socio-emotional communication is important for the satisfaction and motivation of team members and for developing a sense of community. In this genre all CAs are subsumed whose purpose are not directly work-related, such as commending team members or private conversations. Socioemotional communication mostly occurs in conjunction with CAs of other genres. Although social communication happens frequently, the corresponding CAs are very short.

Hence, the purpose of communication is to ensure that all team members are informed on who is doing what and when. The genre can be divided into two sub genres. We term the first one (genre 3a) "agreeing on tasks and their sequence"; it captures the routinized communication with regard to negotiating task distribution among the team members. CAs in this genre comprise two-way communication between two or more team members. The second one (genre $3 \mathrm{~b}$ ) is called "information on task progress" and comprises one-way communication acts by which people send signals to others whenever a preceding task is finished in order for them to be able to begin with their work.

\section{Analysis of media use and propositions for amended media choice}

Based on the identified genre repertoire, every genre is analyzed for its requirements for media support in a next step. For doing so, we collect data on the current media choice and practices of usage in the team. The aim is to derive propositions for improving media choice for the various genres. This analysis is based on the logic of genre-media-fit; as a tool for the analysis serves a classification of media characteristics that has been adapted from existing media choice theories. In the analysis the genres and their media requirements can then be compared to the 
available media and their characteristics, again as perceived in context.

\subsection{Media characteristics as a tool for the analysis}

While media choice theories are of limited use in supporting the actual media choice decision, they are nonetheless useful for identifying a range of criteria to describe various types of media, which can then be used as part of our genre-media-fit analysis. While every theory operates with only a limited set of criteria, a more comprehensive media characterization can be derived by combining several theories. Tab. 1 provides such a list, based on criteria taken from media synchronicity theory (Dennis and Valacich 1999, p. 3), and complemented by other theories. The criteria are used to exemplarily describe some media types.

For example, speech-based media (phone, video) are more prone to creating a rich personal atmosphere than text-based media; they are also capable of transferring a broader set of symbols. Rapid feedback characterizes synchronous media (e. g. meeting or phone), while asynchronous media like e-mail allow rehearsing a message before sending it; they also support reprocessability and automatic documentation of the conversation. The effort for communicating refers to the typical accessibility of media in the user's workspace and the time for setting up a conversation (Sutanto et al. 2004, p. 3). For example, a face-to-face meeting in a virtualized setting might come at the cost of travelling, while phone and instant messenger are most often readily available for ad hoc communication.

Such a generic media characterization often needs to be slightly amended in the context of a particular case, since media are often perceived differently in a social context where social structures and media experience already exist (King and Xia 1997, p. $881 \mathrm{ff}$ ). We also need to point out that our understanding of communication media goes beyond the traditional view in that we acknowledge that communication in practice can also happen implicitly, e. g. via passing on files in a file sharing system. While we still use the term media, we subsume under the concept a richer set of communication and collaboration systems (Riemer et al. 2005).

\begin{tabular}{|c|c|c|c|c|c|c|}
\hline $\mathrm{Nr}$ & Medium & Team members & Same site? & Genre & Scope & Topics and remarks \\
\hline \multirow[t]{5}{*}{1.} & $\begin{array}{l}\text { Meeting } \\
\text { (Jour fixe) }\end{array}$ & $1,3,4,6,8$ & yes & 2 & $5 \min$ & $\begin{array}{l}\text { Circulating air saves } \\
\text { operating costs, but not } \\
\text { installation costs. }\end{array}$ \\
\hline & & & & $3 a$ & $7 \mathrm{~min}$ & $\begin{array}{l}\text { Please take another look } \\
\text { at the installation cost for } \\
\text { the air circulation variant. }\end{array}$ \\
\hline & & & & $3 b$ & $4 \min$ & $\begin{array}{l}\text { The machine casing was } \\
\text { done as discussed earlier. }\end{array}$ \\
\hline & & & & $3 a$ & $8 \min$ & $\begin{array}{l}\text { Can you draw the } \\
\text { foundation plans until } \\
\text { next week? Yes I can. }\end{array}$ \\
\hline & & & & 5 & $8 \mathrm{~min}$ & How was your weekend? \\
\hline 2. & Phone & 6,11 & no & $3 a$ & $10 \mathrm{~min}$ & $\begin{array}{l}\text { Who works on what? What is } \\
\text { currently being worked on? }\end{array}$ \\
\hline 3. & Phone & 7,10 & no & 2 & $6 \min$ & $\begin{array}{l}\text { What about the } \\
\text { shafts? Where are they } \\
\text { located exactly? }\end{array}$ \\
\hline 4. & E-mail & 6,7 & yes & 3a. & 6 lines & $\begin{array}{l}\text { Please draw sketch. With } \\
\text { additional information. }\end{array}$ \\
\hline 5. & Phone & 7,10 & no & $4 a$ & $2 \min$ & $\begin{array}{l}\text { Pre-meeting to coordinate } \\
\text { upcoming meeting. }\end{array}$ \\
\hline (...) & (...) & (...) & (...) & $(\ldots)$ & (...) & (...) \\
\hline
\end{tabular}

\subsection{Analysis and formulation of propositions for improvement}

\subsubsection{Taking stock of existing media use (data collection)}

This (second) data collection phase first aims at the structured recording of current media choice for each genre as the basis for subsequent analysis. For doing so, team members are again observed during their daily work. This time we use a structured observation sheet as instrument in which to record all communication episodes. Specifically, we record all CAs, the corresponding genre and the media being used; we also take note of the team members involved, the scope of communication (time or lines of e-mail), topics, and remarks. We also note down whether team members work at the same site or spatially distributed (see Tab. 2).

Besides documenting media choice for the various CAs with the structured sheet, we also try to capture the (richer) practices of media use through observations and interviews in order to gain a more comprehensive understanding of how people have adopted media. For deriving propositions later, we not only need to know what media are currently being used but also how they are applied. In doing so, we can also immediately become aware of any obvious inefficiencies resulting from media use, which can later serve as a starting point in the analysis. We document media usage practices again in an unstructured way by taking notes.

\subsubsection{Deriving alternative media usage scenarios (analysis of genre-media-fit)}

The goal in this step is to improve the team's genre-media-fit. For doing so, we need to derive the specific requirements for media support for every genre. These requirements can then be compared to the affordances (characteristics) of existing and potential new media (in terms of genre-media-fit).

For deriving requirements, first every genre is analyzed using the list of criteria presented in table 1; some requirements can also be deduced immediately (e. g. the clarification of a time-critical detail requires the medium to immediately inform the recipient of an arriving message). In addition, team members might also be interviewed directly with regard to requirements. In a second step we match the identified requirements with the characteristics of the currently used media in order to identify mismatches and obvious problems. In a third step we then derive a proposition for new media selection that matches better the identified requirements in terms of genre-media-fit. Based on the 


\begin{tabular}{|c|c|c|c|c|}
\hline \multirow[b]{2}{*}{ Genre requirements } & \multicolumn{2}{|l|}{ Current media use } & \multicolumn{2}{|c|}{ Proposed media choice scenarios } \\
\hline & $\begin{array}{l}\text { Co-located: } \\
\text { Meeting or face-to-face talks }\end{array}$ & $\begin{array}{l}\text { Distributed: } \\
\text { Phone / e-mail }\end{array}$ & $\begin{array}{l}\text { Co-located: } \\
\text { Meeting \& electronic white- } \\
\text { board }\end{array}$ & $\begin{array}{l}\text { Distributed: } \\
\text { Phone/IM \& Application- } \\
\text { Sharing }\end{array}$ \\
\hline Rapid feedback possible & Yes & Limited, by using the phone & Yes & $\begin{array}{l}\text { Yes, via phone } \\
\text { conference or IM }\end{array}$ \\
\hline $\begin{array}{l}\text { Possibility to draw in a } \\
\text { directly observable way }\end{array}$ & Yes & $\begin{array}{l}\text { No, a scanned sketch needs } \\
\text { to be sent by e-mail }\end{array}$ & Yes & Yes, with Application Sharing \\
\hline $\begin{array}{l}\text { Possibility to highlight parts } \\
\text { of a plan in a way that is } \\
\text { viewable by all participants } \\
\text { and to draw in existing plans }\end{array}$ & $\begin{array}{l}\text { Yes, if the plan has } \\
\text { been printed before }\end{array}$ & $\begin{array}{l}\text { Cumbersome: plan needs } \\
\text { to be printed, objects be } \\
\text { highlighted, plan to be } \\
\text { scanned and sent by e-mail }\end{array}$ & $\begin{array}{l}\text { Yes, highlighting with } \\
\text { gestures; drawing electro- } \\
\text { nically on the whiteboard }\end{array}$ & Yes, with Application Sharing \\
\hline $\begin{array}{l}\text { Possibility to } \\
\text { communicate concurrent } \\
\text { to the development and } \\
\text { amending of sketches }\end{array}$ & Yes & $\begin{array}{l}\text { No, communication on a } \\
\text { sketch is only possible after } \\
\text { sending it out by e-mail }\end{array}$ & Yes & $\begin{array}{l}\text { Yes, via phone } \\
\text { conference or IM }\end{array}$ \\
\hline $\begin{array}{l}\text { Automatic documentation of } \\
\text { all versions of the plans and } \\
\text { accessibility for participants }\end{array}$ & $\begin{array}{l}\text { No, all participants need } \\
\text { to copy the plans }\end{array}$ & Yes & Yes & Yes \\
\hline Suppression of parallelism & Limited & No & $\begin{array}{l}\text { Yes, because the } \\
\text { whiteboard becomes } \\
\text { the focal eye catcher }\end{array}$ & $\begin{array}{l}\text { No, but controllable } \\
\text { by a moderator }\end{array}$ \\
\hline $\begin{array}{l}\text { Coordination of back and } \\
\text { forth of speaker focus }\end{array}$ & $\begin{array}{l}\text { Yes, through eye } \\
\text { contact and gestures }\end{array}$ & No & $\begin{array}{l}\text { Yes, through eye } \\
\text { contact and gestures }\end{array}$ & $\begin{array}{l}\text { No, but controllable } \\
\text { by a moderator }\end{array}$ \\
\hline
\end{tabular}

documented practices of current media use we are then able to illustrate our propositions by formulating rich usage scenarios that demonstrate the intended changes.

We will illustrate our approach using the case example. Due to space restrictions we will focus on one genre (the discursive plan development). The second data collection phase took five full workdays; in total 520 minutes of communication were recorded, which comprised 70 episodes and 133 CAs. Besides pen and paper we also used a stopwatch for timekeeping and the observation sheet for recording the episodes.

\subsection{Media choice and usage practices in the case example}

Among co-located team members the discursive plan development is carried out in face-to-face conversations such as meetings; these meetings typically consist of two to five different instances of the genre. In cases where team members are distributed across sites, communication is carried out using phones and e-mail. In doing so, one discussion on the same topic might be scattered across several episodes (in one observed example the plan development took two days and a total of 30 minutes of phone conversations and 7 lines of e-mail text).

\subsubsection{Face-to-face discussions in meetings}

As part of a CA of this complex genre several communicative activities typically take place: a version of the plan is presented, pros and cons of the plan are discussed, and a decision is reached whether or not to realize the plan in this particular version. Should the version be rejected, it is usually amended right away and immediately rediscussed. In doing so, new versions are always crafted as paper-based sketches using pen, rulers, and very large sheets of paper so that all people to be able to see the drawing from their seats in the room. The sketches are either drawn on a blank sheet or they are put into existing CADdrawings. In that way, already existing elements can be used for orientation. In order to compare several versions of the same plan, new sketches might be drawn on transparent paper and put on top of the existing plan. Arising questions are being asked and discussed throughout the sketching process. At the end, all relevant results of the discursive plan development are copied by the team members to their own files; this comprises the final version of the plan as well as any specific remarks on the detailed drawings.

\subsubsection{Spatially distributed discussion using e-mail and phone}

In the distributed version of the genre, we observed the following shared practice: At the beginning, a new version of a plan is drawn on paper; this version is then computerized using scanning equipment and sent to all necessary team members via e-mail. When all team members have examined the sketch, the various aspects of the plan are being discussed in bilateral conversations over the phone. Should the team deem necessary to change the existing version, one team member either prints out the plan to make some amendments or a new version is drawn on paper. This sketch is then again be computerized and the above process is repeated until consensus is reached on a final version of the plan.

\subsection{Analysis of media choice in the case example}

\subsubsection{Deriving requirements for media support}

The discursive plan development is characterized by a high degree of interactivity; a medium should thus provide instant feedback and also support rapid back and forth of speaker focus. Moreover, it should only allow little parallelism, since all 
participants should at all times focus their attention on the same object during activities of developing and assessing versions of the plan. An important characteristic of the genre is that verbal utterances usually refer to specific visual materials. Also, plans are drawn collaboratively during the meeting. During discussions certain objects or parts of the plan need to be highlighted. Consequently, a medium should allow the collaborative and interactive handling and highlighting of objects in a plan. Another characteristic is that many versions of the plan are being developed and ultimately discarded. Hence, the effort for developing and amending a version should be very low; feedback and clarification of technical questions should be enabled concurrently to the plan development. At the end of the CA, the resulting version of the plan should be immediately accessible for all team members, in order to ensure that they all work on the same data from here on (automatic documentation).

\subsubsection{Proposition of alternative media for improving communication}

Tab. 3 compares the above-identified requirements with the characteristics of the current set of media and presents our proposition for improving media choice in the genre. It becomes obvious that especially the distributed practices were deemed inefficient (marked grey).

In order to avoid printing plans and copying sketches in the co-located meeting, we propose to use an electronic whiteboard with which team members are able to jointly and interactively develop ideas and concepts in digital form during the workshop situation. In doing so, all plans are being held digitally; they can be projected onto the digital board and be manipulated in real-time by using a special pen for drawing on the board. Highlighting of certain parts of the plan can be done by using the mouse pointer or with a simple gesture.

In case of distributed work the use of application-sharing software can significantly simplify the shared practice. Combined with media for synchronous group communication (phone conference or instant messaging) plans can be interactively and collaboratively crafted and discussed immediately. In addition, by using an integrated meeting system such software can be hooked up with the co-located meeting in that its picture is projected onto the board. In that way, the two formerly isolated practices can be merged together in order to significantly improve communicative action in this genre. In both cases, all results are available in electronic form at the end of the process. Moreover, these solutions can significantly reduce the cost for paper and printing.

\section{Discussion and future method development}

In the previous sections we have illustrated how with the help of genre analysis we are able to contextualize media choice for application in a single case. Our next goal is to further develop our genre-based approach and turn it into a more comprehensive method for communication analysis that can be used in a consultancy context. To that end, we will first discuss the main findings that resulted from the application of our approach in the case example before we will provide an outlook on further method development.

\subsection{Findings from application in the case example}

As the result of our analysis we proposed to introduce the following new media in the case example: an electronic whiteboard (for the meeting room) and an application sharing solution for improving discursive plan development activities (genre 1), an instant messaging solution for enabling ad hoc communication for clarifying technical details (genre 2) and for better coordination of communication (genre 4a) as well as a document management solution for improving information on task progress (genre 3b). Our propositions were presented and discussed in a joint workshop with team members, members of the company board, and IT representatives.

\subsubsection{Genres as medium for communication with users}

The presentation of our media proposals led to a discussion among the team members that was controversial at times. For example, there were initial reservations regarding the benefits of instant messaging ("we do not need chat", "the social will get lost"). However, it turned out that with the help of the identified genres and the understanding of the existing practices of media use we were able to immediately clarify the intended benefits of applying the proposed media. In doing so, it was possible to illustrate, in a comprehensible and accessible way, how work and communication practices would have to change with the new media. In that way, it was possible to quickly convince the team members of the proposed changes.

These experiences from the workshop illustrate another advantage of the genrebased approach: In the literature communication systems are portrayed as open and flexible systems (Orlikowski 1992) whose concrete benefits cannot be derived from only scrutinizing their features (Riemer et al. 2007a) as might be the case with other IT artifacts. Against this backdrop, genres allow illustrating the benefits of proposed media changes as well as possible ways of application in a vivid and much richer way as would be possible by simply presenting new communication tools and their features.

\subsubsection{Incorporate users as active participants in the approach}

During our case study it became obvious that users should not be regarded as passive receivers, but as active designers of their own communication environment who reflect upon their own media use and who can serve as valuable discussants in the process of data collection and analysis (see also Lee 1994, p. 155). Consequently, team members should be consulted in both the identification of genres and the analysis of current media use. And since the users' personal attitudes have an influence on media use and might thus potentially hinder the later adoption (Chidambaram et al. 1998b, p. 3), it is important to illustrate as concrete as possible the intended benefits and potential use of the propositions in the final workshop discussion (see above). Also, the results of our approach should be treated as propositions for change and as input to a discussion with the team members and not as the objectively best solution to an abstract problem.

\subsubsection{Evaluation of the approach in the case example}

An evaluation of our approach based on its application in the case example is difficult since the study was not set up as a formal evaluation but as an applied research step in the process of method development. 


\begin{tabular}{|c|c|c|c|c|c|c|c|}
\hline \multicolumn{2}{|c|}{ Data collection } & \multirow{2}{*}{$\begin{array}{l}\text { Analysis } \\
\text { Identify } \\
\text { genres }\end{array}$} & Data collection & \multicolumn{2}{|c|}{ Analysis } & Implementation & \multirow{2}{*}{$\begin{array}{c}\text { Evaluation } \\
\begin{array}{l}\text { Evaluate } \\
\text { changes }\end{array}\end{array}$} \\
\hline $\begin{array}{l}\text { Capture } \\
\text { context }\end{array}$ & $\sum_{\text {communication }}^{\text {Observe }}$ & & $\begin{array}{l}\text { Observe } \\
\text { media use }\end{array}$ & $\begin{array}{l}\text { Identify } \\
\text { requirements }\end{array}$ & $\begin{array}{l}\text { Formulate } \\
\text { scenarios }\end{array}$ & $\begin{array}{c}\text { Prepare } \\
\text { implementation }\end{array}$ & \\
\hline $\begin{array}{l}\text { Gain understanding } \\
\text { of team context. } \\
\text { Data on: } \\
\text { company structure, } \\
\text { products, culture, } \\
\text { team structures, } \\
\text { work tasks, } \\
\text { available media } \\
\text { etc. }\end{array}$ & $\begin{array}{l}\text { Observe \& record } \\
\text { communication, } \\
\text { carry out interviews } \\
\text { Unstructured data } \\
\text { collection using a } \\
\text { journal: } \\
\text {-comm. episodes } \\
\text {-comm. acts }\end{array}$ & $\begin{array}{l}\text { Qualitative data } \\
\text { analysis: recorded } \\
\text { CAs are being } \\
\text { coded by purpose } \\
\text { Discuss genre } \\
\text { candidates with the } \\
\text { team members } \\
\text { Result: } \\
\text { genre repertoire }\end{array}$ & $\begin{array}{l}\text { Again observation: } \\
\text { Media choice is } \\
\text { recorded in a more } \\
\text { structure way using } \\
\text { observation sheet } \\
\text { Also: } \\
\text { describe media } \\
\text { use practices }\end{array}$ & $\begin{array}{l}\text { For every genre: } \\
\text { derive } \\
\text { requirements for } \\
\text { media support } \\
\text { (use table 1) } \\
\text { Discuss the } \\
\text { requirements with } \\
\text { team members. }\end{array}$ & $\begin{array}{l}\text { Evaluate current } \\
\text { media selection by } \\
\text { juxtaposing media } \\
\text { characteristics and } \\
\text { genre requirements } \\
\text { Propose new } \\
\text { media and sketch } \\
\text { out usage with a } \\
\text { set of scenarios. }\end{array}$ & $\begin{array}{l}\text { Illustrate intended } \\
\text { use of new media } \\
\text { during a workshop } \\
\text { with team and } \\
\text { company reps. } \\
\text { Prioritize changes. } \\
\text { Prepare process of } \\
\text { implementation. }\end{array}$ & $\begin{array}{l}\text { Evaluate media } \\
\text { adoption and } \\
\text { changes some time } \\
\text { after introduction. } \\
\text { Observation and } \\
\text { interviews. } \\
\text { Identifiy necessary } \\
\text { adaptations. }\end{array}$ \\
\hline
\end{tabular}

Fig. 3 Outline of a procedure model for the communication analysis method

The feedback however is very encouraging; the team members were immediately able to identify with the genre repertoire, and both management and team members uttered satisfaction with our media propositions.

The company's decision to implement most of our propositions is another indicator for the success of the application in the case example. For example, an electronic whiteboard has already been purchased and installed in a meeting room at the Aachen headquarters. Moreover, the company is piloting the introduction of IBM Lotus Sametime, an integrated solution providing instant messaging, video conferencing, and application sharing support. However, an evaluation of the use and benefits of these solutions has to be carried out at a later point in time.

\subsection{Future steps in the development of the method}

The aim of future research is to turn the presented approach into a comprehensive method for communication analysis in distributed teams.

\subsubsection{Constituent elements of a method}

Methods comprise several constituent elements (Braun et al. 2005, p. 1297). The approach presented in this paper already introduces the main activities and the core phases of a procedure model. This model however has to be complemented with additional phases such as an implementation and an evaluation phase (see Fig. 3).

With the genre analysis we also introduced the main technique for carrying out the communication analysis. Other techniques that are applied as part of the method are qualitative data collection and analysis techniques. However, as a further step we need to develop tools or instru- ments that make the techniques more accessible for application in practice. We already presented our observation sheet as one such instrument. Moreover, we need to determine typical roles and their responsibilities in applying the method in practice.

\subsubsection{Limitations of the approach as starting point for future research}

The application in the case example revealed a major limitation of the approach in its current state. In the case, we collected rich, unstructured data that were analyzed following a grounded theory approach (Bryman and Bell 2003, p. 427). While the effort was within normal limits of a qualitative research study, we will develop more structured instruments in order to support the efficient application in the context of management consulting. One such tool could be a generic genre catalogue that helps with the identification of genres in context; possible genre candidates are: context-specific communication, work coordination, meta communication, knowledge sharing, socio-emotional communication.

Another limitation arises in virtualized and highly mobile contexts where observing communication becomes impossible since people are travelling most of the time. Here, other forms of data collection need to complement the existing tools, such as the sending out of semi-structured questionnaires.

\subsubsection{Application of the method in practice}

As with other methods, our approach will require consultants to acquire a certain set of skills in using the various techniques and instruments. Hence, the necessary competencies should be documented and be made accessible in the form of trainings and materials. In doing so, the required skills mainly stem from the application of qualitative research methods (observation and interview techniques, qualitative data analysis for genre identification); such competencies are already well documented in the literature (e. g. Hopf 1995, p. 181) and can thus be adapted.

\subsubsection{Open questions with regard to method evaluation}

The method finally needs to be evaluated in line with the recommendations for design-oriented research. In this context a range of open questions exist which should guide future research: 1) How can the method evaluation be set up methodologically? 2) Is it possible (and sensible) to compare directly the results of our approach with recommendations drawn from traditional media choice theories? 3) How can improvements through changes in media choice be 'measured' or evaluated? In our case, this was based on a judgment by the team members. 4) Is it even possible to come up with an objective evaluation? 5) If yes, what are useful criteria (efficiency, effectiveness, satisfaction etc.)?

\section{Conclusion}

Starting from a critique of traditional media choice theories in this paper we presented an approach for contextualizing media choice using genre analysis; its application was illustrated using a case example. We have argued that our approach has certain advantages compared to media choice theories. First, media choice is not determined based on abstract, isolated tasks (or similar constructs). While the approach still follows a fit-logic, it intro- 
duces with the genre construct a different kind of reference object that captures the rich communication practices that have emerged in the social team context. In doing so, our approach is based on the assumption that a team has already built out practices of communication and media use. The approach is thus not readily able to support media choice in newly formed teams without a shared history. On the other hand, the approach takes into account, in sharp contrast to media choice theories, that in most teams some form of media use already exists, which needs to be considered when proposing changes.

Moreover, due to its embedding in the social context our approach can tap into the rich experiences and know how of the team members in carrying out the analysis. The approach is also promising in communicating the results to the team members because with the genres it is possible to illustrate the intended media use changes in rich and vivid ways, which goes beyond a mere presentation of tools and features.

With regard to the media construct we want to point out again that we have based our approach on a wider understanding of communication media that takes into account the combination of media, complex media bundles, and also implicit communication through other types of information systems. While in the case example our analysis implicitly accounted for the combination of media (see section 5.4), research in this area is still scarce. Consequently, future research should investigate the effects of combining media, especially with regard to users' cognitive load and also the compatibility and interaction effects between different types of media.

\section{References}

Alge BJ, Wiethoff C, Klien HJ (2003) When does medium matter? Knowledge building experiences and opportunities in decision-making teams. Organizational Behavior and Human Decisions Processes 92:26-37

Antunes P, Costa CJ, Pino JA (2006) The use of genre analysis in the design of electronic meeting systems. Ir - informationresearch 11(3). http://informationr.net/ir/11-13/paper251.html.

Arnott DR, Tan WD (2001) Managerial Information acquisition and the world wide web: an exploratory study. In: 5th pacific asia conference on information systems. Seoul, pp 749-760

Askehave I, Swales JM (2001) Genre identification and communicative purpose: a problem and a possible solution. Applied Linguistics
22(2):195-212

Bakhtin MM (1986) Speech genres and other late essays. Austin

Berkenkotter C, Huckin TN (1995) Genre knowledge in disciplinary communication: cognition, culture, power. Hillsdale, New Jersey

Bitzer L (1968) The rhetorical situation. Philosophy and Rhetoric 1:1-14

Bortz J, Döring N (2006) Forschungsmethoden und Evaluation für Human- und Sozialwissenschaftler, 4th edn. Springer, Heidelberg

Braun C, Wortmann F, Hafner M, Winter R (2005) Method construction - a core approach to organizational engineering. ACM symposium on applied computing. Santa Fe, pp 1295-1299

Bryman A, Bell E (2003) Business research methods. Oxford University Press, New York

Bungard W, Holling H, Schultz-Gambard J (1996) Methoden der Arbeits- und Organisationspsychologie. Psychologie Verlags Union, Weinheim

Carlson JR, Zmud RW (1999) Channel expansion theory and the experiential nature of media richness perceptions. Academy of Management Journal 42(2):153-170

Carlson PJ, Davis GB (1998) An investigation of media selection among directors and managers: from "self" to "other" orientation. MIS Quarterly 22(3):335-362

Chidambaram L, Lim LH, Chan HC (1998a) The media coexistence approach - organizational and individual determinants of media choice in Singapore. 31st Hawaii international conference on system sciences. Kohala Coast, pp 1-9

Chidambaram L, Moe CE, Olsen DH (1998b) A study of factors influencing media choice in norwegian organizations. 31st Hawaii international conference on system sciences. Kohala Coast, pp 1-10

Daft RL, Lengel RH (1984) Information richness. a new approach to managerial behavior and organization design. Research in Organizational Behavior 6:191-233

Daft RL, Lengel RH, Trevino LK (1987) Message equivocality, media selection, and manager performance: implications for information systems. MIS Quarterly 11(3):355-366

Dennis AR, Fuller RM, Valacich JS (2008) Media, tasks, and communication processes: a theory of media synchronicity. MIS Quarterly 32(3):575-600

Dennis AR, Valacich JS (1999) Rethinking media richness: towards a theory of media synchronicity. 32nd Hawaii international conference on system sciences. Los Alamitos, IEEE Computer Society, pp 1-10

Dennis AR, Valacich JS, Speier C, Morris MG (1998) Beyond media richness: an empirical test of media synchronicity theory. 31st Hawaii international conference on system sciences. Los Alamitos, IEEE Computer Society

DeSanctis G, Poole MS (1994) Capturing the complexity in advanced technology use: adaptive structuration theory. Organization Science 5(2):121-147

Flick U (1998) An introduction to qualitative research. Sage, London

Frank U, Kronen J (1991) Kommunikationsanaly-
Abstract

Kai Riemer, Stefanie Filius

\section{Contextualizing Media Choice Using Genre Analysis}

Value creation is increasingly organized in virtualized settings requiring effective computer-mediated communication. While media choice has been a topic of interest in Information Systems for some time, corresponding media choice theories exhibit a range of shortcomings with regard to applicability in context. Since the theories try to generalize across social contexts, their key constructs are rather abstract and underspecified with regard to application. Against this backdrop we present an approach for contextualizing media choice using genre analysis. Genre analysis aims at identifying communication patterns (genres) in social communities (e. g. teams) as a structured overview of existing team communication. By juxtaposing requirements of the identified genres and media characteristics, we are able to propose a new set of media for improving team communication. We illustrate the application of our approach with a case example.

Keywords: Media choice, Genre analysis, Communication analysis, Virtualization, Teamwork, Virtual teams 
severfahren - Theoretische Konzepte, Anwendungspraxis und Perspektiven zur Gestaltung von Informationssystemen. Vieweg, Wiesbaden

Fulk J, Schmitz J, Steinfield C (1990) A social influence model of technology use. In: Fulk J, Steinfield C (eds) Organizations and Communication Technology. Sage, Newburry Park, pp 117-140

Giddens A (1984) The constitution of society. Outline of the theory of structuration. Cambridge

Herrmann T (1991) Die Bedeutung menschlicher Kommunikation für die Kooperation und für die Gestaltung computerunterstützter Gruppenarbeit. In: Oberquelle H (eds) Kooperative Arbeit und Computerunterstützung. Stand und Perspektiven. Verlag für Angewandte Psychologie, Göttingen, pp 63-78

Hopf C (1995) Befragungsverfahren. In: Flick U, von Kardorff E, KeuppH, von Rosenstiel L, Wolff $S$ (eds) Handbuch Qualitative Sozialforschung. Psychologie-Verl.-Union, Weinheim, pp 177188

Huang W, Watson RT, Wei KK (1998) Can a lean e-mail medium be used for rich communication? A psychological perspective. Europ J Information Systems 7:269-274

King RC, Xia W (1997) Media appropriateness: effects of experience on communication media choice. Decision Sciences 28(4):877-910

Kinney ST, Watson RT (1992) The effect of medium and task on dyadic communicaiton. 13th international conference on information systems. Dallas, pp 107-117

Kwasnik BH, Crowston K (2005) Introduction to special issue: genres of digital documents. Information Technology \& People 18(2):76-88

Lee AS (1994) Electronic mail as a medium for rich communication: an empirical investigation using hermeneutic interpretation. MIS Quarterly 18(2):143-157

Lee Z, Lee Y (2003) Cultural implications of electronic communication usage:, a theory-based empirical analysis. 24th international conference on information systems. Seattle, pp 630 641

Markus ML (1994) Electronic mail as the medium of managerial choice. Organization Science 5(4):502-526

Miles MB, Huberman AM (1994) Qualitative data analysis: an expanded sourcebook, 2nd edn. Sage, Thousand Oaks

Olson GM, Olson JS (2000) Distance matters. Human Computer Interaction 15(2):139-178

Orlikowski WJ (1992) The duality of technology: rethinking the concept of technology in organizations. Organization Science 3(3):398-427

Orlikowski WJ (2000) Using technology and constituting structures: a practice lens for studying technology in organizations. Organization Science 11(4):404-428

Orlikowski WJ (2002) Knowing in practice: enacting a collective capability in distributed organizing. Organization Science 13(3):249-273

Orlikowski WJ, Yates Y (1994) Genre repertoire: the structuring of communicative practices in organizations. Administrative Science Quarterly 39:541-574

Otondo RF, Van Scotter JR, Allen DG, Palvia
$\mathrm{P}(2008)$ The complexity of richness: media, message, and communication outcomes. Information \& Management 45:21-30

Pauleen DJ, Yoong P(2001) Relationship building and the use of ICT in boundary-crossing virtual teams: a facilitator's perspective. J Information Technology 16:205-220

Reichwald R, Möslein K, Sachenbacher H, Englberger H, Oldenburg S (1998) Telekooperation. Verteilte Arbeits- und Organisationsformen. Springer, Heidelberg

Reid FJM, Malinek V, Stott CJT, Evans JSBT (1996) The messaging treshold in computer-mediated communication. Ergonomics 39(8):1017-1037

Rice RE, Aydin C (1991) Attitudes toward new organizational technology: network proximity as a mechanism for social information processing. Administrative Science Quarterly 36:219-244

Riemer K, Arendt P, Wulf A (2005) Marktstudie Kooperationssysteme. Von E-Mail über Groupware zur Echtzeitkooperation. Göttingen

Riemer K, Frößler F, Klein S (2007a) Real time communication - modes of use in distributed teams. 15th european conference on information systems (ECIS 2007). St. Gallen, pp 286-297 Riemer K, Klein S (2008) Is the V-form the next generation organisation? An analysis of challenges, pitfalls and remedies of ICT-enabled virtual organisations based on social capital theory. Journal of Information Technology (JIT) 23(3):147-162

Riemer K, Klein S, Flößler F (2007b) Towards a practice understanding of the creation of awareness in distributed work. Proceedings of the twenty-eighth international conference on information systems

Riemer K, Vehring N, Klein S (2008) Adoption of communication media in virtual organisations - case evidence of structural dilemmas. 16th european conference on information systems (ECIS), Galway

Rosenstiel L (2003) Grundlagen der Organisationspsychologie, 5th edn. Schäffer-Poeschel, Stuttgart

Schwabe G (2001) Theorien zur Mediennutzung bei der Gruppenarbeit. In: Schwabe G, Streitz $\mathrm{N}$, Unland R (eds) CSCW-Kompendium. Lehrund Handbuch zum computerunterstützten kooperativen Arbeiten. Heidelberg, pp 54-56

Schwabe G (2004) Medienwahl. In: Haake J, Schwabe G, Wessner M (eds) CSCL-Kompendium. Lehr- und Handbuch zum computergestützten kooperativen Lernen. Oldenbourg, München, pp 258-267

Scupelli P, Kiesler S, Fussell SR, Chen C (2005) Project view IM: a tool for juggling multiple projects and teams. Proceedings of the $\mathrm{CHI} 2005$. Portland, pp 1773-1776

Short J, Williams E, Christie B (1976) The social psychology of telecommunications. London

Strauss AL (1998) Grundlagen qualitativer Sozialforschung. Datenanalyse und Theoriebildung in der empirischen und soziologischen Forschung. München

Sutanto J, Phang CW, Kankanhalli A, Tan BCY (2004) Towards a process model of media usage in global virtual teams. 12th european conference on information systems. Turku
Swales JM (1990) Genre analysis: english in academic and research settings. Cambridge

Trevino LK, Daft RL, Lengel RH (1990) Understanding manager's media choices: a symbolic interactionist perspective. In: Fulk J Steinfield C (eds) Organizations and communication technology. Sage, Newbury Park, pp 71-94

Watson-Manheim MB, Bélanger F (2002) An indepth investigation of communication mode choices in ditributed teams. 23rd international conference on information systems. Barcelona, pp 871-876

Watson-Manheim MB, Bélanger F (2007) Communication media repertoires: dealing with the multiplicity of media choices. MIS Quarterly 31(2):267-293

Yates JA, Orlikowski WJ (1992) Genres of organizational communication: a structurational approach to studying communication and media. Academy of Management Review 17(2):299326

Yates Y, Orlikowski WJ (1994) Genre repertoire: examining the structuring of communication practices in organizations. Administrative Science Quarterly 39:541-574

Yates Y, Orlikowski WJ, Okamura K (1999) Explicit and implicit structuring of genres: electronic communication in a japanese R\&D organization. Organization Science 10(1):83-103

Yin RK (2003) Case study research: design and methods, 3rd edn. Sage, Thousand Oaks

Yoo Y, Alavi M (2001) Media and group cohesion: relative influences on social presence, task participation, and group consensus. MIS Quarterly 25(3):371-390

Yoshioka T, Herman G, Yates JA, Orlikowski WWJ (2001) Genre taxonomy: a knowledge repository of communicative actions. ACM Transactions on Information Systems 19(4):431-456

Zack MH, McKenny JL (1995) Social context and interaction in ongoing computer-supported management groups. Organization Science 6(4):394-422 